\title{
Strategi Peningkatan Kinerja Dengan Metode Balance Scorecard (Studi Kasus Pada Hotel Puri Khatulistiwa Jatinangor)
}

\author{
Muhammad Ardi Nupi Hasyim¹, Hanny Novindaning Tyas², I Gede Putu Brahmantta Bismahogra \\ Budiswara $^{3}$, Isni Tazkiatul Ulla ${ }^{4}$ \\ 1,2,3,4 Prodi S1-Akuntansi Institut Manajemen Koperasi Indonesia \\ e-mail : ${ }^{1}$ ardi.nupi@yahoo.com, ${ }^{2}$ novindaninghanny@gmail.com, ${ }^{3}$ puturama7@gmail.com, \\ 4isnitazkia88@gmail.com
}

\begin{abstract}
Abstrak - Puri Khatulistiwa Hotel merupakan perusahaan yang bergerak di bidang jasa perhotelan yang memiliki 69 kamar. Selama ini Puri Khatulistiwa Hotel hanya menggunakan analisis laporan keuangan untuk mengukur kinerja perusahaan. Pengelolaan kinerja Puri Khatulistiwa Hotel seharusnya mempertimbangkan keseimbangan antara aspek keuangan dan non keuangan. Penelitian ini bertujuan untuk mengetahui kinerja Hotel Puri Khatulistiwa dengan metode analisis yang digunakan adalah dengan Balanced Scorecard yang dilihat melalui 4 perspektif. Populasi dalam penelitian ini adalah seluruh karyawan hotel dan pelanggan hotel. Teknik pengambilan sampel dengan menyebarkan kuesioner kepada karyawan dan pelanggan Hotel Puri Khatulistiwa. Dasar yang digunakan dalam pengambilan sampel secara random, sampel penelitian yang digunakan 30 orang karyawan dan sebanyak 20 orang pelanggan. Berdasarkan analisis kinerja yang telah didapat dengan menggunakan metode Balanced Scorecard, maka diperoleh kesimpulan : (1) Perspektif proses bisnis internal yaitu inovasi adalah baik dengan adanya inovasi - inovasi bisnis yang dijalankan. (2) Perspektif pembelajaran dan bertumbuh adalah dengan mengukur kepuasan karyawan, retensi karyawan, dan kemampuan sistem informasi. Kepuasan karyawan diperoleh 7,55\% dikategorikan baik, retensi karyawan cukup baik, dan kemampuan sistem informasi diperoleh 1,6\% dikategorikan baik. (3) Perspektif pelanggan adalah dilihat dari hasil penyebaran kuesioner karakteristik responden dan kepuasan pelanggan menunjukan pelanggan puas terhadap pelayanan Hotel Puri Khatulistiwa.. (4) Perspektif keuangan adalah baik dilihat dari beberapa aspek yang telah dijelaskan.
\end{abstract}

Kata Kunci : Analisis Kinerja, Balanced Scorecard, Hotel.

Abstract - Puri Khatulistiwa Hotel is a company engaged in the field of hospitality services which has 69 rooms. So far, Puri Khatulistiwa Hotel only uses financial statements analysis to measure company performance. Managing the performance of Puri Khatulistiwa Hotel should consider a balance between financial and nonfinancial aspects. This study aims to determine the performance of the Puri Khatulistiwa Hotel with the analysis method used is the Balanced Scorecard seen through 4 perspectives. The population in this study were all hotel employees and hotel customers. The sampling technique is by distributing questionnaires to employees and customers of the Puri Khatulistiwa Hotel. The basis used in random sampling, the research sample used 30 employees and as many as 20 customers. Based on the performance analysis that has been obtained using the Balanced Scorecard method, the following conclusions are obtained : (1) Internal Business Process perspective, namely innovation is good with the existence of bussines innovations that are run. (2) Learning and Growth perspective is to measure employee satisfaction, employee retention, and information system capabilities. Employee satisfaction obtained by 7,55\% is categorized good, employee retention is quite good, and the ability of the information system obtained by 1,6\% is categorized good. (3) Customer perspective is seen from the results of the distribution of respondents characteristics questionnaires and customer satisfaction shows customers are satisfied with the Puri Khatulistiwa Hotel services. (4) Financial perspective is good from several aspects that have been described.

Keywords : Performance Anaysis, Balanced Scorecard, Hotel

\section{PENDAHULUAN}

Perusahaan adalah suatu institusi yang bertujuan untuk menciptakan kekayaan bisnis yang dijalankannya (Mulyadi, 2001) Dunia bisnis saat ini berlangsung dalam iklim yang sangat kompetitif. Perusahaan dituntut untuk lebih meningkatkan kinerja dalam persaingan bisnis dengan perbaikan kualitas kinerja. Sistem pengukuran kinerja perusahaan kebanyakan masih menggunakan system pengukuran tradisional, yaitu hanya mengukur kinerja berdasarkan aspek keuangan (financial). Ukuran keuangan (Financial) saja tidak dapat memberikan gambaran yang real mengenai keadaan 
perusahaan yang sesungguhnya, karena mudah dimanipulasi sesuai dengan kepentingan manajemen.

Dengan meningkatnya persaingan antara pengusaha perhotelan. Pihak manajemen hotel akan mempersiapkan strategi - strategi untuk dapat bersaing. Pengusaha perhotelan perlu mengukur kinerja bisnis mereka untuk mengetahui seberapa jauh efektifitas penerapan strategi tersebut. Pengelola hotel perlu mengetahui apakah strategi - strategi yang telah ditempuh telah berjalan dengan efektif, efesien, ekonomis, untuk mencapai tujuan dari hotel yang dikelola.

Metode Balance Scorecard merupakan alternative pemilihan pengukuran kinerja perusahaan. Metode Balance Scorecard merupaka seperangkat ukuran yang memberikan pandangan menyeluruh mengenai bisnis kepada para Manajer secara cepat dalam lingkungan yang kompleks untuk sukses dalam persaingan. Dalam Balance Scorecard dapat menjadi indikasi peringatan awal dari keberhasilan dan kegagalan bagi perusahaan secara lebih menyeluruh dari sisi financial, pelanggan, proses bisnis internal dan pembelajaran.

"Penilaian kinerja dengan Balanced Scorecard pada awalnya banyak digunakan oleh organisasi yang berorientasi pada pencapaian laba (profit oriented), tetapi sejalan dengan perkembangannya penilaian kinerja pada organisasi sektor publik sudah mulai menggunakan penilaian kinerja dengan Balance Scorecard" (Nugrahini et al., 2016).

Keunggulan pendekatan Balance Scorecard adalah untuk dapat memberikan ukuran yang dapat dijadikan sebagai dasar dalam perbaikan strategis. Berdasarkan latar belakang masalah yang telah diuraikan, maka dalam penelitian ini penulis tertarik untuk menyusun Jurnal dengan metode ini.

Sebuah penelitian membahasa tentang penggunaan metode Balance Scorecard dalam sebuah organisasi nirlaba (Cattarougus County bintang Pusat Rehabilitas) dalam proses perencanaan strategis. Pusat rehabilitas memfokuskan pada perspektif konsumen dan keuangan yang didasarkan pada kebutuhan pusat untuk melaksanakan misi utama untuk konsumen serta kebutuhan untuk menjaga stabilitas keuangan. Tantangan kedepan Pusat Rehabilitas adalah untuk terus mengembangkan ukuran hasil dari masing-masing departemen untuk tujuan strategis pusat dalam jangka panjang.

Hasil penelitian yang dilakukan oleh (Gimzauskiene \& Valanciene, 2010) menunjukkan bahwa sistem pengukuran kinerja dalam organisasi Lithuanian akan efisien dan efektif ketika bersifat multidimensi. Korelasi kuat antara keuangan, pasar, pelanggan, proses internal, dan langkah-langkah terkait intelektual membuktikan bahwa hasil keuangan adalah titik akhir kinerja organisasi yang dapat dikelola sambil mengelola factor nonkeuangan seperti pelanggan, proses, dan modal intelektual.

Hasil beberapa penelitian yang telah dilakukan membuktikan bahwa metode Balance Scorecard dipandang cukup komprehensif dalam mengukur kinerja perusahaan. Penelitian ini akan mendeskripsikan hubungan sebab akibat dari empat perspektif dalam Balance Scorecard dengan mengukur kinerja perusahaan berdasarkan pada persentase pertumbuhan atau penurunan dalam mencapai target di setiap tahunnya. Hasil akhir dari pengukuran kinerja dengan metode Balance Scorecard dijadikan sebagai bahan pertimbangan untuk perbaikan strategi perusahaan di masa yang akan datang.

Puri Khatulistiwa Hotel merupakan perusahaan yang bergerak di bidang jasa perhotelan yang memiliki 69 kamar. Selama ini Puri Khatulistiwa Hotel hanya menggunakan analisis laporan keuangan untuk mengukur kinerja perusahaan. Pengelolaan kinerja Puri Khatulistiwa Hotel seharusnya mempertimbangkan keseimbangan antara aspek keuangan dan non keuangan.

Berdasarkan permasalahan di atas maka tujuan dari penelitian ini adalah untuk mengukur pencapaian kinerja Puri Khatulistiwa Hotel dengan menggunakan kriteria Balance Scorecard sehingga perusahaan dapat mengevaluasi kinerja perusahaan secara keseluruhan untuk dapat memenangkan persaingan industri jasa perhotelan.

Balanced Scorecard mengembangkan seperangkat tujuan unit bisnis melampaui rangkuman ukuran finansial, yang mampu membuat eksekutif perusahaan megukur seberapa unit bisnis mereka menciptakan nilai bagi para pelanggan perusahaan saat ini dan yang akan datang, serta seberapa banyak perusahaan harus meningkatkan kapabilitas internal dan investasi dalam sumber daya manusia.

"Balanced Scorecard dikembangkan pada tahun 1993 oleh dua profesor Harvard Business School, Robert Kaplan dan David Norton. Menurut (R. Kaplan \& Norton, 2016) Balanced Scorecard adalah suatu kerangka kerja baru untuk mengintegrasikan berbagai ukuran yang diturunkan dari strategi perusahaan. Menurut Tunggal Balanced Scorecard merupakan kelompok tolak ukur kinerja yang terintegrasi yang berasal dari strategi perusahaan dan mendukung strategi perusahaan di seluruh organisasi. David menyatakan bahwa Balanced Scorecard merupakan sebuah proses yang memungkinkan perusahaan mengevaluasi strategi dari empat perspektif: kinerja keuangan, pengetahuan konsumen, proses bisnis internal, serta pembelajaran dan pertumbuhan" (Styaningrum et al., 2014). 
Berdasarkan beberapa pengertian di atas maka dapat disimpulkan bahwa Balanced Scorecard merupakan suatu sistem pengukuran kinerja dengan suatu pendekatan efektif yang seimbang (Balanced) antara empat perspektif yang berbeda yaitu perspektif keuangan, perspektif pelanggan, perspektif proses bisnis internal, serta perspektif pembelajaran dan pertumbuhan.

\section{Perspektif Balanced Scorecard}

1. Perspektif Finansial

"Terdapat empat sub-tujuan perspektif yang dapat memicu kinerja keuangan perusahaan secara keseluruhan, yaitu menaikkan pendapatan dan margin atas pelanggan yang ada; memperluas penjualan dengan pelanggan, produk, dan pasar baru; mengurangi biaya per unit produksi produk dan jasa; serta meningkatkan pemanfaatan aset" (Styaningrum, 2015).

Profitabilitas ialah suatu ukuran perusahaan untuk mendapatkan peraturan/ Laba yang terdapat hubungan dengan penjualan, total aktiva, dan modal sendiri” (Agung et al., 2019).

\section{Perspektif Pelanggan}

"Kepuasan merupakan perasaan senang atau kecewa seseorang yang berasal dari perbandingan antara kesan dari kinerja produk dengan harapannya" (Simarmata et al., 2017).

Dalam perspektif pelanggan Balanced Scorecard, para manajer mengidentifikasi pelanggan dan segmen pasar di mana unit bisnis tersebut akan bersaing dan berbagai ukuran kinerja unit bisnis di dalam segmen pasar. Perspektif ini biasanya terdiri atas beberapa ukuran utama atau ukuran generic keberhasilan perusahaan dari strategi yang dirumuskan dan dilaksanakan dengan baik. Ukuran utama tersebut terdiri atas kepuasan pelanggan, retensi pelanggan, akuisisi pelanggan baru, profitabilitas pelanggan, dan pangsa pasar di segmen sasaran. Perspektif pelanggan memungkinkan para manajer unit bisnis untuk mengartikulasikan strategi yang berorientasi kepada pelanggan dan pasar yang akan memberikan keuntungan finansial masa depan yang lebih besar.

3. Perspektif Proses Bisnis Internal

Dalam perspektif proses bisnis internal, para eksekutif mengidentifikasi berbagai proses internal penting yang harus dikuasai dengan baik oleh perusahaan. Proses ini memungkinkan unit bisnis untuk :

- Memberikan proposisi nilai yang akan menarik perhatian dan mempertahankan pelanggan dalam segmen pasar sasaran, dan
- Memenuhi harapan keuntungan finansial yang tinggi para pemegang saham

Perspektif proses bisnis internal mengungkapkan dua perbedaan ukuran kinerja yang mendasar antara pendekatan tradisional dengan pendekatan BCS. Pendekatan tradisional berusaha memantau dan meningkatkan proses bisnis yang ada saat ini. Pendekatan ini mungkin melampaui ukuran kinerja finansial dalam hal pemanfaatan alat ukur yang berdasar kepada mutu dan waktu. Tetapi semua ukuran itu masih berfokus pada peningkatan proses bisnis saat ini. Sedangkan pendekatan scorecard pada umumnya akan mengidentifikasi berbagai proses baru yang harus dikuasai dengan baik oleh sebuah perusahaan agar dapat memenuhi berbagai tujuan pelanggan dan finansial.

"Setiap perusahaan memiliki seperangkat proses penciptaan nilai yang unik bagi pelanggannya dan memberikan hasil finansial yang baik. Secara umum, (R. S. Kaplan \& Norton, 1996) membaginya menjadi tiga prinsip dasar, yaitu: a. Inovasi, proses inovasi dibagi menjadi dua bagian yaitu mengidentifikasi kebutuhan pasar dan menciptakan produk atau jasa untuk memenuhi kebutuhan pasar tersebut. b. Operasi, tahap ini mencerminkan aktivitas yang dilakukan oleh perusahaan mulai dari penerimaan order dari konsumen, pembuatan produk sampai dengan pengiriman produk kepada pelanggan. c. Pelayanan Purna Jual, tahap ini perusahaan berupaya untuk memberikan manfaat tambahan kepada para pelanggan yang telah memberi produkproduknya dalam berbagai layanan purna transaksi jual-beli, seperti garansi, aktivitas perbaikan dan proses pembayaran" (Kurniasari \& Memarista, 2017).

4. Perspektif Pembelajaran dan Pertumbuhan

Perspektif keempat dari Balanced Scorecard, pembelajaran dan pertumbuhan, mengidentifikasi infrastruktur yang harus dibangun perusahaan dalam menciptakan pertumbuhan dan peningkatan kinerja jangka panjang. Perspektif pelanggan dan proses bisnis internal mengidentifikasi faktor-faktor yang paling penting untuk mencapai keberhasilan pada saat ini dan masa depan. Tiga sumber utama pembelajaran dan pertumbuhan perusahaan dating dari : manusia, sistem, dan prosedur perusahaan.

"Pembelajaran dan pertumbuhan menekankan pada keahlian dan kemampuan karyawan, teknologi, dan keterpaduan organisasi yang akan memicu perbaikan di sejumlah proses 
penentu keberhasilan dalam pembelajaran dan pertumbuhan” (Styaningrum, 2015).

\section{Keunggulan dan Kelemahan Balanced Scorecard}

"Menurut (Mulyadi, 2001) keunggulan konsep balanced scorecard dalam sistem perencanaan strategik adalah mampu menghasilkan rencana strategik yang me- miliki karakteristik; (a) komprehensif, yaitu balance scorecard memperluas prespektif yang dicakup dalam perencanaan strategik. Perluasan perspektif rencana strategik ke prespektif non keuangan tersebut menghasilkan manfaat, antara lain kemampuan organisasi untuk memasuki lingkungan bisnis yang komplek; (b) Koheren, yaitu balanced scorecard mewajibkan personil untuk membangun hubungan sebab akibat di antara berbagai sasaran strategik yang dihasilkan dalam perencanaan strategik; (c) Berimbang, yaitu keseimbangan sasaran strategik yang dihasilkan oleh sistem pe- rencanaan strategik penting untuk menghasilkan kinerja keuangan berjangka pan- jang; (d) Terukur, yaitu keterukuran sasaran strategik yang dihasilkan oleh sistem pe- rencanaan strategik menjanjikan ketercapaian berbagai sasaran strategik yang dihasilkan oleh sistem tersebut" (Sumani, 2016).

"Sedikitnya ada 4 kelemahan dalam membuat dan memasukan ukuran serta sistem manajemen bar uke organisasi, yaitu :

1. Manajemen senior tidak berkomitmen

2. Tanggung jawab Balanced Scorecard tidak mengalir ke bawah.

3. Solusi dirancang berlebihan atau Balanced Scorecard diperlukan sebagai peristiwa satu kali.

4. Balanced Scorecard diperlukan sebagai sistem atau proyek konsultasi" (Styaningrum et al., 2014).

\section{Kinerja Perusahaan}

"Kinerja adalah suatu tampilan keadaan secara utuh atas perusahaan selama periode waktu tertentu" (Putra, 2014). Kinerja perusahaan adalah hasil dari kegiatan manajemen. Parameter yang sering digunakan untuk menilai kinerja suatu perusahaan yang dilakukan dengan menggunakan pendekatan dimana informasi keuangan diambil dari laporan keuangan atau laporan keuangan lainnya. Tujuan penilaian kinerja adalah memotivasi personal dalam mencapai sasaran oragnisasi dan mematuhi standar agar membuahkan tindakan serta hasil yang diinginkan oleh organisasi.
Penilaian kinerja dilakukan guna perbaikan organisasi secara berkesinambungan, karena bagi setiap organisasi khususnya organisasi bisnis merupakan suatu keharusan. Hal ini dilihat dari tingginya persaingan antar perusahaan. Penilaian kinerja diperlukan agar terciptanya peningkatan kualitas kinerja dan pengaruhnya lebih jauh pada peningkatan produktivitas serta profit perusahaan. Tujuan lain penilaian kinerja bagi semua pihak adalah agar mereka mengetahui manfaatyang mereka harapkan.

Pengukuran kinerja merupakan suatu alat manajemen yang digunakan untuk meningkatkan kualitas pengambilan keputusan dan akuntabilitas, serta untuk menilai pencapaian tujuan dan sasaran (goal sand objectives)" (Galib \& Hidayat, 2018).

\section{METODE PENELITIAN}

Penelitian ini menggunakan pendekatan penelitian kualitatif. Penelitian kualitatif mengkaji perspektif partisipan dengan strategi-strategi yang bersifat interaktif dan fleksibel. Penelitian kualitatif ditunjukkan untuk memahami fenomena-fenomena social dari sudut pandang partisipan. Dengan demikian, penelitian kualitatif adalah penelitian yang digunakan untuk meneliti pada kondisi objek alamiah dimana peneliti merupakan instrumen kunci (sugiono, 2011)

Penelitian ini dilakukan di Puri Khatulistiwa Hotel berlokasi di Jl. Raya Jatinangor, No.208 C Rt.02 Rw.02 45363, cibeusi kec.Jatinangor, Kab.Sumedang Jawa Barat. Untuk mendapatkan informasi atau data dan yang dibutuhkan dalam penelitian ini akan menggunakan data sebagai berikut

1. Data primer : data yang diperoleh secara langsung dari sumbernya, diamati dan dicatat untuk pertama kalinya;

2. Data sekunder : data yang dibutuhkan diusahakan sendiri pengumpulannya oleh peneliti.

Data primer dapat juga diperoleh melalui kuisioner, interview, dan observasi, sedangkan data sekunder dapat juga diperoleh dari data-data dokumenter.

Pengumpulan data yang digunakan dalam penelitian ini adalah :

1. Wawancara

Wawancara merupakan pertemuan dua orang untuk bertukar informasi dan ide melalui tanya jawab, sehingga dapat dikontruksikan maknanya kepada suatu 
topik tertentu (sugiono, 2011) mengutip pendapatan wawancara (interview) yaitu dialog atau tanya jawab yang dilakukan pewawancara untuk memperoleh informasi dari responden terwawancara.

2. Kuisioner

Kuisioner adalah metode pengumpulan data dengan cara mengajukan perrtanyaan tertulis kepada responden. Kuisioner dalam penelitian ini bersifat tertutup yaitu hanya menjawab pertanyaanpertanyaan dengan memberikan tanda silang terhadap jawaban-jawaban yang tersedia yang dianggap sesuai.

\section{HASIL DAN PEMBAHASAN}

Hotel Puri Khatulistiwa adalah salah satu hotel yang ada dikota Bandung yang kini menjadi hotel bagi kalangan bisnis dan wisatawan. Hotel Puri Khatulistiwa terletak di J1 Raya Jatinangor pada KM 20 , dengan luas tanah $\pm 9800 \mathrm{~m}^{2}$ yang mempunyai 4 lantai dengan jumlah kamar 69.

Pengukuran kinerja hotel berdasarkan Balanced Scorecard menggunakan empat perspektif, yaitu Perspektif Proses Bisnis Internal, Perspektif Pembelajaran dan Pertumbuhan, Perspektif Pelanggan dan Perspektif Keuangan. Berikut analisis kinerja pada Hotel Puri Khatulistiwa berdasarkan metode Balanced Scorecard :

\section{1) Perspektif Proses Bisnis Internal}

Analisis kinerja perspektif proses bisnis internal pada Hotel Puri Khatulistiwa dengan pendekatan balanced scorecard adalah proses usaha internal. Di dalam mengukur kinerja usaha internal ini didasarkan pada inovasi.

Dalam pembobotan aspek proses usaha internal tersebut, penulis asumsikan bahwa proses inovasi merupakan suatu proses mengidentifikasi kebutuhan masyarakat, sehingga perusahaan mampu survive dan bahkan mampu berkembang jika melaksanakan fungsi inovasi tersebut, tetapi hal terpenting dan harus dilaksanakan dalam setiap organisasi adalah proses yang bekerja untuk mengolah input menjadi output yang baik.

Aspek usaha internal mencakup beberapa bidang usaha Hotel Puri Khatulistiwa sebagai usaha di bidang jasa telah berkembang unit-unit usaha, dapat dilihat dari pembuatan unit-unit baru sebagai pengembangan dari unit usaha yang sudah ada, yaitu

1. Swimming Pool

Merupakan fasilitas berenang bagi tamu kamar dan diperuntukan pula untuk umum sebagai penambah penghasilan dengan harga untuk berenang sebesar Rp. 40.000

2. Laundry

Fasilitas jasa cuci pakaian bagi tamu hotel.

\section{Fitness Center}

Fasilitas untuk tamu berupa ruang olahraga.

4. Restaurant 24 Jam

Fasilitas tempat makan bagi tamu yang selalu buka selama 24 jam demi kenyamanan ketersediaan pelayanan.

5. Karaoke

Ruang karaoke untuk tamu.

Selain itu Hotel Puri Khatulistiwa memiliki Function Room atau Ruang Meeting antara lain :

1. Khatulistiwa Convention Hall dengan kapasitas 1000 orang dan memiliki luas ruangan sebesar $800 \mathrm{~m} 2$.

2. Borneo Room dengan kapasitas 100 orang dan luas ruangan sebesar $125 \mathrm{~m} 2$.

3. Sumba Room dengan kapasitas 100 orang dan luas ruangan $110 \mathrm{~m} 2$.

4. Banda Room dengan kapasitas 100 orang dan luas ruangan $110 \mathrm{~m} 2$.

5. Tropical Room dengan kapasitas 30 orang dan luas ruangan sebesar $80 \mathrm{~m} 2$.

6. Nusantara Room dengan kapasitas 200 orang dan luas sebesar $336 \mathrm{~m} 2$.

7. Java Room dengan kapasitas 75 orang dan luas ruangan $90 \mathrm{~m} 2$.

8. Natuna Room dengan kapasitas $10-15$ orang dan luas ruangan $40 \mathrm{~m} 2$.

Dari analisis strategi perhotelan dengan merambah berbagai bisnis menjadikan bertambahnya income perhotelan Puri Khatulistiwa Hotel .

\section{2) Perspektif Pembelajaran dan Bertumbuh}

(Mahmudah, 2015), “(R. S. Kaplan \& Norton, 1996) memasukan aspek ini bertujuan untuk mendorong perusahaan menjadi organisasi belajar (learning organization), mendorong pertumbuhan, dan sekaligus untuk mendukung pencapaian ketiga aspek yaitu Kepuasan Karyawan, retensi Karyawan, dan Kemampuan Sistem Informasi. Pendapat tersebut, skor yang diberikan terhadap aspek ini sebesar 20\% dari keseluruhan aspek yang terdapat dalam pendekatan balanced scorecard. Untuk perincian skor, dapat dilihat dalam diagram berikut

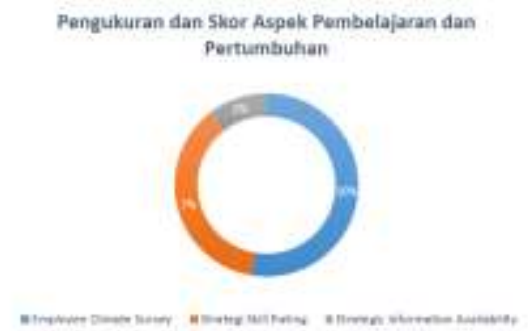

Gambar 1. Pengukuran dan Skor Aspek Pembelajaran dan Pertumbuhan 
Employee Climate Survey penulis kategorikan dalam kepuasan karyawan, dimana penulis ingin mengetahui sejauh mana lingkungan perusahaan mempengaruhi karyawan dalam bersikap, berperilaku, dan bertindak. Sedangkan Strategic Skill Rating ini merupakan tingkat keahlian seseorang untuk melakukan tugasnya dengan baik, sehingga perusahaan berusaha mempertahankan agar karyawan tersebut tetap bertahan dan memberikan kontribusi pada perusahaan. Dan untuk Strategic Information Availability akan diketahui melalui kemudahan dalam mendapatkan dan mengakses informasi yang dibutuhkan bagi karyawan." Penulis menggunakan Skala Likert dengan empat skala pilihan dimana 1 = Pernah, 2 = Jarang, 3 = Kadangkadang, dan 4 = Sering untuk menentukan tingkat persetujuan responden terhadap suatu pernyataan dengan memilih salah satu dari pilihan yang tersedia.

\section{Kepuasan Karyawan}

Kepuasan karyawan merupakan suatu tingkatan karyawan di mana organisasi dapat memuaskan kebutuhan karyawan. Dalam hal ini karyawan hotel dalam memberikan pelayanan kepada para tamu. Kualitas Sumber Daya Manusia yang dimiliki merupakan faktor penting yang membentuk kepuasan pelanggan. Dalam penelitian tentang kepuasan karyawan terdapat 20 item yang diturunkan ke dalam 20 pertanyaan, yaitu sebagai berikut :

Tabel 1. Penyertaan Tentang Kepuasan Karyawan

\begin{tabular}{|c|c|c|c|}
\hline No & Item & No & Item \\
\hline 1 & Perhatian Kesehatan & 1 & Komunikasi \\
\hline 2 & $\begin{array}{c}\text { Gaji Sesuai } \\
\text { Kompetensi }\end{array}$ & 2 & Pelayanan \\
\hline 3 & Jaminan Hari Tua & 3 & $\begin{array}{c}\text { Penciptaan } \\
\text { Suasana }\end{array}$ \\
\hline 4 & $\begin{array}{c}\text { Jaminan Sosial } \\
\text { Tenaga Kerja }\end{array}$ & 4 & Ketanggapan \\
\hline 5 & Kerja Sama & 5 & Inisiatif \\
\hline 6 & $\begin{array}{c}\text { Hubungan Atasan } \\
\text { dan Karyawan }\end{array}$ & 6 & Kehadiran \\
\hline 7 & Penghargaan & 7 & Tepat Waktu \\
\hline 8 & Kedudukan & 8 & Kepatuhan \\
\hline 9 & $\begin{array}{c}\text { Pencapaian Target } \\
\text { Pekerjaan }\end{array}$ & 9 & Tunjangan \\
\hline 10 & Sikap & 10 & Hak Cuti \\
\hline
\end{tabular}

Untuk data selengkapnya yang berhubungan dengan tanggapan responden terhadap tingkat kepuasan karyawan Hotel Puri Khatulistiwa dapat dilihat dalam Tabel berikut :

Tabel 2. Hasil Kuesioner Tingkat Kepuasan Karyawan

\begin{tabular}{|c|l|c|c|c|c|c|}
\hline \multirow{2}{*}{$\begin{array}{c}\mathrm{N} \\
\mathrm{o}\end{array}$} & \multirow{2}{*}{ Item } & \multicolumn{4}{|c|}{ Tingkat Kepuasan } & TOTA \\
\cline { 2 - 6 } 1 & & 1 & 2 & 3 & 4 & $\mathrm{~L}$ \\
\hline 1 & Perhati & 4 & 7 & 17 & 2 & 30 \\
& an & 13.3 & 23.3 & 56.6 & 06.6 & 100.00 \\
& Keseha & $3 \%$ & $3 \%$ & $7 \%$ & $7 \%$ & $\%$ \\
& tan & & & & & \\
\hline
\end{tabular}

\begin{tabular}{|c|c|c|c|c|c|c|}
\hline 2 & $\begin{array}{l}\text { Gaji } \\
\text { Sesuai } \\
\text { Kompe } \\
\text { tensi }\end{array}$ & $\begin{array}{c}0 \\
00.0 \\
0 \%\end{array}$ & $\begin{array}{c}0 \\
00.0 \\
0 \%\end{array}$ & $\begin{array}{c}27 \\
90.0 \\
0 \%\end{array}$ & $\begin{array}{c}3 \\
10.0 \\
0 \%\end{array}$ & $\begin{array}{c}30 \\
100.00 \\
\%\end{array}$ \\
\hline 3 & $\begin{array}{l}\text { Jamina } \\
\text { n Hari } \\
\text { Tua }\end{array}$ & $\begin{array}{c}3 \\
10.0 \\
0 \% \\
\end{array}$ & $\begin{array}{c}12 \\
40.0 \\
0 \%\end{array}$ & $\begin{array}{c}11 \\
36.6 \\
7 \%\end{array}$ & $\begin{array}{c}4 \\
13.3 \\
3 \% \\
\end{array}$ & $\begin{array}{c}30 \\
100.00 \\
\%\end{array}$ \\
\hline 4 & $\begin{array}{l}\text { Jamina } \\
\mathrm{n} \\
\text { Sosial } \\
\text { Tenaga } \\
\text { Kerja }\end{array}$ & $\begin{array}{c}0 \\
00.0 \\
0 \%\end{array}$ & $\begin{array}{c}8 \\
26.6 \\
7 \%\end{array}$ & $\begin{array}{c}18 \\
60.0 \\
0 \%\end{array}$ & $\begin{array}{c}4 \\
13.3 \\
3 \%\end{array}$ & $\begin{array}{c}30 \\
100.00 \\
\%\end{array}$ \\
\hline 5 & $\begin{array}{l}\text { Kerja } \\
\text { Sama }\end{array}$ & $\begin{array}{c}0 \\
00.0 \\
0 \%\end{array}$ & $\begin{array}{c}0 \\
00.0 \\
0 \%\end{array}$ & $\begin{array}{c}14 \\
46.6 \\
7 \%\end{array}$ & $\begin{array}{c}16 \\
53.3 \\
3 \%\end{array}$ & $\begin{array}{c}30 \\
100.00 \\
\%\end{array}$ \\
\hline 6 & $\begin{array}{l}\text { Hubun } \\
\text { gan } \\
\text { Atasan } \\
\text { dan } \\
\text { Karyaw } \\
\text { an }\end{array}$ & $\begin{array}{c}0 \\
00.0 \\
0 \%\end{array}$ & $\begin{array}{c}1 \\
03.3 \\
3 \%\end{array}$ & $\begin{array}{l}24 \\
80 \\
\%\end{array}$ & $\begin{array}{c}5 \\
16.6 \\
7 \%\end{array}$ & $\begin{array}{c}30 \\
100.00 \\
\%\end{array}$ \\
\hline 7 & $\begin{array}{l}\text { Pengha } \\
\text { rgaan }\end{array}$ & $\begin{array}{c}10 \\
33.3 \\
3 \% \\
\end{array}$ & $\begin{array}{l}15 \\
50 \\
\% \\
\end{array}$ & $\begin{array}{c}5 \\
16.6 \\
7 \% \\
\end{array}$ & $\begin{array}{c}4 \\
13.3 \\
3 \% \\
\end{array}$ & $\begin{array}{c}30 \\
100.00 \\
\% \\
\end{array}$ \\
\hline 8 & $\begin{array}{l}\text { Kedudu } \\
\text { Kan }\end{array}$ & $\begin{array}{c}0 \\
00.0 \\
0 \% \\
\end{array}$ & $\begin{array}{c}2 \\
06.6 \\
7 \% \\
\end{array}$ & $\begin{array}{c}27 \\
90.0 \\
0 \% \\
\end{array}$ & $\begin{array}{c}1 \\
03.3 \\
3 \% \\
\end{array}$ & $\begin{array}{c}30 \\
100.00 \\
\%\end{array}$ \\
\hline 9 & $\begin{array}{l}\text { Pencap } \\
\text { aian } \\
\text { Target } \\
\text { Pekerja } \\
\text { an }\end{array}$ & $\begin{array}{c}0 \\
00.0 \\
0 \%\end{array}$ & $\begin{array}{c}2 \\
06.6 \\
7 \%\end{array}$ & $\begin{array}{c}27 \\
90.0 \\
0 \%\end{array}$ & $\begin{array}{c}1 \\
03.3 \\
3 \%\end{array}$ & $\begin{array}{c}30 \\
100.00 \\
\%\end{array}$ \\
\hline 10 & Sikap & $\begin{array}{c}0 \\
00.0 \\
0 \% \\
\end{array}$ & $\begin{array}{c}0 \\
00.0 \\
0 \% \\
\end{array}$ & $\begin{array}{c}16 \\
53.3 \\
3 \% \\
\end{array}$ & $\begin{array}{c}14 \\
46.6 \\
7 \% \\
\end{array}$ & $\begin{array}{c}30 \\
100.00 \\
\%\end{array}$ \\
\hline 11 & $\begin{array}{l}\text { Komun } \\
\text { ikasi }\end{array}$ & $\begin{array}{c}0 \\
00.0 \\
0 \% \\
\end{array}$ & $\begin{array}{c}0 \\
00.0 \\
0 \% \\
\end{array}$ & $\begin{array}{c}23 \\
76.6 \\
7 \% \\
\end{array}$ & $\begin{array}{c}7 \\
23.3 \\
3 \% \\
\end{array}$ & $\begin{array}{c}30 \\
100.00 \\
\% \\
\end{array}$ \\
\hline 12 & $\begin{array}{l}\text { Pelayan } \\
\text { an }\end{array}$ & $\begin{array}{c}0 \\
00.0 \\
0 \% \\
\end{array}$ & $\begin{array}{c}0 \\
00.0 \\
0 \% \\
\end{array}$ & $\begin{array}{l}15 \\
50 \\
\% \\
\end{array}$ & $\begin{array}{l}15 \\
50 \\
\% \\
\end{array}$ & $\begin{array}{c}30 \\
100.00 \\
\%\end{array}$ \\
\hline 13 & $\begin{array}{l}\text { Pencipt } \\
\text { aan } \\
\text { Suasan } \\
\text { a }\end{array}$ & $\begin{array}{c}0 \\
00.0 \\
0 \%\end{array}$ & $\begin{array}{c}0 \\
00.0 \\
0 \%\end{array}$ & $\begin{array}{c}26 \\
86.6 \\
7 \%\end{array}$ & $\begin{array}{c}4 \\
13.3 \\
3 \%\end{array}$ & $\begin{array}{c}30 \\
100.00 \\
\%\end{array}$ \\
\hline 14 & $\begin{array}{l}\text { Ketang } \\
\text { gapan }\end{array}$ & $\begin{array}{c}0 \\
00.0 \\
0 \% \\
\end{array}$ & $\begin{array}{c}0 \\
00.0 \\
0 \% \\
\end{array}$ & $\begin{array}{c}27 \\
90.0 \\
0 \% \\
\end{array}$ & $\begin{array}{c}3 \\
10.0 \\
0 \% \\
\end{array}$ & $\begin{array}{c}30 \\
100.00 \\
\% \\
\end{array}$ \\
\hline 15 & Inisiatif & $\begin{array}{c}1 \\
03.3 \\
3 \% \\
\end{array}$ & $\begin{array}{c}3 \\
10.0 \\
0 \% \\
\end{array}$ & $\begin{array}{c}26 \\
86.6 \\
7 \% \\
\end{array}$ & $\begin{array}{c}0 \\
00.0 \\
0 \% \\
\end{array}$ & $\begin{array}{c}30 \\
100.00 \\
\%\end{array}$ \\
\hline 16 & $\begin{array}{l}\text { Kehadi } \\
\text { ran }\end{array}$ & $\begin{array}{c}0 \\
00.0 \\
0 \%\end{array}$ & $\begin{array}{c}0 \\
00.0 \\
0 \% \\
\end{array}$ & $\begin{array}{c}20 \\
66.6 \\
7 \% \\
\end{array}$ & $\begin{array}{c}10 \\
33.3 \\
3 \% \\
\end{array}$ & $\begin{array}{c}30 \\
100.00 \\
\%\end{array}$ \\
\hline 17 & $\begin{array}{l}\text { Tepat } \\
\text { Waktu }\end{array}$ & $\begin{array}{c}0 \\
00.0 \\
0 \% \\
\end{array}$ & $\begin{array}{c}0 \\
00.0 \\
0 \% \\
\end{array}$ & $\begin{array}{l}21 \\
70 \\
\% \\
\end{array}$ & $\begin{array}{c}9 \\
30.0 \\
0 \% \\
\end{array}$ & $\begin{array}{c}30 \\
100.00 \\
\% \\
\end{array}$ \\
\hline 18 & $\begin{array}{l}\text { Kepatu } \\
\text { han }\end{array}$ & $\begin{array}{c}0 \\
00.0 \\
0 \% \\
\end{array}$ & $\begin{array}{c}0 \\
00.0 \\
0 \% \\
\end{array}$ & $\begin{array}{c}24 \\
80.0 \\
0 \% \\
\end{array}$ & $\begin{array}{c}6 \\
20.0 \\
0 \% \\
\end{array}$ & $\begin{array}{c}30 \\
100.00 \\
\% \\
\end{array}$ \\
\hline
\end{tabular}




\begin{tabular}{|c|l|c|c|c|c|c|}
\hline 19 & Tunjan & 2 & 17 & 11 & 0 & 30 \\
& gan & 06.6 & 56.6 & 36.6 & 00.0 & 100.00 \\
& & $7 \%$ & $7 \%$ & $7 \%$ & $0 \%$ & $\%$ \\
\hline 20 & Hak & 0 & 4 & 23 & 3 & 30 \\
& Cuti & 00.0 & 13.3 & 76.6 & 10.0 & 100.00 \\
& & $0 \%$ & $3 \%$ & $7 \%$ & $0 \%$ & $\%$ \\
\hline \multicolumn{2}{|l|}{ Jumlah } & 20 & 71 & 402 & 111 & 600 \\
& & 03.3 & 11.8 & 67.0 & 18.0 & $100 \%$ \\
\hline
\end{tabular}

Gambar 3. Hasil Kuesioner Tingkat Kepuasan Karyawan

Dengan jawaban yang telah dilakukan oleh karyawan tentang tingkat kepuasan karyawan Hotel Puri Khatulistiwa maka hasil perhitungan rata-rata untuk tingkat kepuasan adalah sebagai berikut :

$$
\frac{(20 \times 1)(71 \times 2)(402 \times 3)(111 \times 4)}{(30 \times 20)}=3,02
$$

Dari jawaban tingkat kepuasan karyawan Hotel Puri Khatulistiwa, dapat diketahui bahwa tingkat kepuasan berada pada kontimum puas dan sangat puas. Berdasarkan hasil tingkat kepuasan karyawan sebesar 3,02 tersebut, maka diketahui bobot ukuran kepuasan karyawan adalah sebesar $7,55 \%$.

\section{Retensi Karyawan}

Selain aspek kepuasan karyawan, kinerja belajar dan bertumbuh juga diukur dengan retensi karyawan, dimana Hotel Puri Khatulistiwa mempertahankan para karyawannya. Kemampuan Hotel Puri Khatulistiwa mempertahankan karyawannya dapat diukur dengan menggunakan indikator berupa tingkat perputaran karyawan (labour turnover index), tetapi sebelumnya akan ditunjukan daftar mutasi karyawan Hotel Puri Khatulistiwa yang dapat dilihat dalam tabel berikut :

Tabel 3. Daftar Mutasi Karyawan Hotel Puri Khatulistiwa Tahun 2018 Dan 2019

\begin{tabular}{|c|c|c|c|c|}
\hline Tahun & $\begin{array}{c}\text { Per } \\
\text { Januari }\end{array}$ & Keluar & Masuk & $\begin{array}{c}\text { Per 31 } \\
\text { Desember }\end{array}$ \\
\hline 2018 & 68 & 2 & 7 & 73 \\
\hline 2019 & 73 & 8 & 10 & 75 \\
\hline
\end{tabular}

Berdasarkan tabel diatas diketahui bahwa jumlah karyawan Hotel Puri Khatulistiwa dari tahun 2018 ke tahun 2019 mengalami perubahan, tidak pernah tetap. Jumlah karyawan terbanyak yang dimiliki oleh Hotel Puri Khatulistiwa pada tahun 2019 yaitu 75 orang sedangkan jumlah terendah adalah pada tahun 2018 yaitu sebanyak 73 orang. Jumlah karyawan yang keluar maupun yang masuk selalu ada setiap tahunnya, hal ini umum terjadi pada setiap organisasi yang merupakan dinamikanya suatu perusahaan. Selanjutnya untuk melihat tingkat retensi karyawan di Hotel Puri Khatulistiwa yang dilakukan berdasarkan perhitungan Labour turnover index (Sumber: Pratt \& Bennett, dalam Candra Wijaya, 1997: 19), maka dapat dilihat dalam tabel berikut :

\section{"Labour \\ Turnover \\ $=$ $\frac{\text { Numbere of Leavers in Period }}{\text { Average Number Employed During Period }} \times 100^{\prime \prime}$}

(Mahmudah, 2015).

Tabel 4. Tingkat Perputaran Karyawan Hotel Puri Khatulistiwa Tahun 2018 Dan 2019

\begin{tabular}{|c|c|c|}
\hline No & Tahun & Indeks \\
\hline 1 & 2018 & 2,84 \\
\hline 2 & 2019 & 10,81 \\
\hline & Rata-rata & $\mathbf{1 3 , 6 5}$ \\
\hline
\end{tabular}

Dari tabel di atas terlihat bahwa indeks perputaran karyawan rata-rata selama dua tahun sebesar 13,65 dan indeks tertinggi terjadi pada tahun 2019 yaitu dengan indeks 10,81. Angka indeks tersebut dapat dikatakan tinggi, jika dibandingkan dengan rata-rata tingkat perputaran karyawan untuk organisasi sejenis. Berdasarkan perhitungan tersebut, maka hasil perputaran karyawan Hotel Puri Khatulistiwa adalah sebagai berikut :

$(10,81 / 13,65) \times 100 \%=79,20$

$(2,84 / 13,65) \times 100 \%=20,81$

Atas hasil perputaran karyawan tersebut, maka dapat diketahui bobot ukuran retensi karyawan sebesar 3,8\%. Hal ini dapat diartikan bahwa Hotel Puri Khatulistiwa cukup mampu mempertahankan karyawannya.

\section{Kemampuan Sistem Informasi}

Kemampuan sistem informasi memberi dukungan kepada karyawan untuk menyempurnakan proses pelaksanaan, dan memerlukan umpan balik yang cepat, tepat waktu, dan teliti. Tolak ukur kemampuan sistem informasi meliputi tingkat ketersediaan informasi, ketepatan informasi, dan waktu yang diperlukan untuk mendapatkan informasi.

Kuesioner untuk kemampuan sistem informasi tersebut hanya diberikan kepada 30 karyawan yang juga menjadi sampel dalam tingkat kepuasan karyawan. Untuk mengetahui sejauh mana kemampuan sistem informasi diperoleh oleh karyawan Hotel Puri Khatulistiwa, maka dapat dilihat dalam tabel 5: 
Tabel 5. Jawaban Kemampuan Sistem Informasi Hotel Puri Khatulistiwa

\begin{tabular}{|c|c|c|c|c|c|c|}
\hline \multirow{2}{*}{$\begin{array}{l}\mathrm{N} \\
\mathrm{O}\end{array}$} & \multirow{2}{*}{$\begin{array}{c}\text { PERTAN } \\
\text { YAA }\end{array}$} & \multicolumn{4}{|c|}{ JAWABAN } & \multirow{2}{*}{$\begin{array}{c}\text { TOTA } \\
\mathrm{L}\end{array}$} \\
\hline & & 1 & 2 & 3 & 4 & \\
\hline \multirow[t]{3}{*}{1} & Tingkat & 0 & 0 & 19 & 11 & 30 \\
\hline & Ketersedia & 00.0 & 00.0 & 63.3 & 36.6 & 100.0 \\
\hline & $\begin{array}{l}\text { an } \\
\text { Informasi }\end{array}$ & $0 \%$ & $0 \%$ & $3 \%$ & $7 \%$ & $0 \%$ \\
\hline \multirow[t]{3}{*}{2} & Keakurata & 0 & 0 & 25 & 5 & 30 \\
\hline & & 00.0 & 00.0 & 83.3 & 16.6 & 100.0 \\
\hline & Informasi & $0 \%$ & $0 \%$ & $3 \%$ & $7 \%$ & $0 \%$ \\
\hline \multirow[t]{6}{*}{3} & Waktu & 0 & 0 & 22 & 8 & 30 \\
\hline & Mendapat & 00.0 & 00.0 & 73.3 & 26.6 & 100.0 \\
\hline & $\begin{array}{l}\text { kan } \\
\text { Informasi }\end{array}$ & $0 \%$ & $0 \%$ & $3 \%$ & $7 \%$ & $0 \%$ \\
\hline & JUMLAH & 0 & 0 & 66 & 24 & 90 \\
\hline & & 00.0 & 00.0 & 73.3 & 26.6 & 100.0 \\
\hline & & $0 \%$ & $0 \%$ & $3 \%$ & $7 \%$ & $0 \%$ \\
\hline
\end{tabular}

Dari tabel terlihat bahwa kemampuan sistem informasi yang menyangkut tingkat ketersediaan informasi, tingkat keakuratan informasi, dan waktu yang diperlukan untuk mendapatkan informasi adalah baik. Perhotelan dengan terbuka memberikan informasi apa saja yang diperlukan untuk kelancaran tugas para karyawannya.

Dengan jawaban tentang tingkat kemampuan sistem informasi tersebut, maka hasil rata-rata perhitungan tingkat kemampuan sistem informasi sebagai berikut :

$$
\frac{(0 \times 1)+(0 \times 2)+(66 \times 3)+(24 \times 4)}{30 \times 3}=3,27
$$

Dari jawaban tingkat kemampuan sistem informasi yang diperoleh karyawan Hotel Puri Khatulistiwa mendapatkan hasil 3,27 maka dapat diketahui bobot ukuran kepuasan karyawan adalah $1,6 \%$ yaitu baik.

Dari bobot masing-masing ukuran dalam aspek belajar dan bertumbuh tersebut, maka dapat disimpulkan bahwa bobot kinerja aspek belajar dan bertumbuh adalah :

Tabel 6. Pengukuran dan skor aspek pembelajaran dan bertumbuh hotel puri khatulistiwa

\begin{tabular}{|l|l|c|}
\hline No & \multicolumn{1}{|c|}{ Pengukuran } & Skor (\%) \\
\hline 1 & Kepuasan Karyawan & $7,55 \%$ \\
\hline 2 & Retensi Karyawan & $3,8 \%$ \\
\hline 3 & $\begin{array}{l}\text { Kemampuan Sistem } \\
\text { Informasi }\end{array}$ & $1,6 \%$ \\
\hline & Jumlah & $\mathbf{1 2 , 9 5 \%}$ \\
\hline
\end{tabular}

\section{3) Perspektif Pelanggan}

Pada penelitian perspektif pelanggan digunakan cara menyebar kuesioner terhadap 20 responden. Karakteristik responden dapat dilihat dari data berikut :

Tabel 7. Kuesioner Responden Pelanggan Hotel Puri Khatulistiwa

\begin{tabular}{|c|c|c|c|}
\hline NO & $\begin{array}{l}\text { PERTAN } \\
\text { YAAN }\end{array}$ & $\begin{array}{l}\text { KARAKTERIS } \\
\text { TIK }\end{array}$ & JUMLAH \\
\hline \multirow[t]{2}{*}{1.} & \multirow{2}{*}{$\begin{array}{l}\text { JENIS } \\
\text { KELAMI } \\
\mathrm{N} \\
\end{array}$} & Laki - laki & 12 \\
\hline & & Perempuan & 8 \\
\hline \multirow[t]{5}{*}{2.} & \multirow[t]{5}{*}{ USIA } & 20 - 30 tahun & 6 \\
\hline & & $31-40$ tahun & 8 \\
\hline & & $41-50$ tahun & 4 \\
\hline & & $51-60$ tahun & 2 \\
\hline & & diatas 60 tahun & 0 \\
\hline \multirow[t]{5}{*}{3.} & \multirow[t]{5}{*}{ Pekerjaan } & $\begin{array}{l}\text { Pegawai } \\
\text { negeri/BUMN }\end{array}$ & 6 \\
\hline & & Pegawai swasta & 6 \\
\hline & & $\begin{array}{l}\text { Wiraswasta/pen } \\
\text { gusaha }\end{array}$ & 4 \\
\hline & & $\begin{array}{l}\text { Pelajar/mahasis } \\
\text { wa }\end{array}$ & 3 \\
\hline & & Lainnya & 1 \\
\hline \multirow[t]{2}{*}{4.} & \multirow{2}{*}{$\begin{array}{l}\text { ASAL } \\
\text { DAERAH }\end{array}$} & Asli Bandung & 8 \\
\hline & & $\begin{array}{l}\text { dari luar } \\
\text { Bandung }\end{array}$ & 12 \\
\hline \multirow[t]{6}{*}{5.} & \multirow{6}{*}{$\begin{array}{l}\text { JUMLAH } \\
\text { PENGHA } \\
\text { SILAN } \\
\text { PER } \\
\text { BULAN } \\
\text { (BAGI } \\
\text { YANG } \\
\text { SUDAH } \\
\text { BEKERJA } \\
\text { ) }\end{array}$} & $\begin{array}{l}\text { Kurang dari Rp. } \\
1 \text { juta }\end{array}$ & 2 \\
\hline & & Rp. 1 - 3 juta & 3 \\
\hline & & Rp. 3 - 5 juta & 5 \\
\hline & & Rp. 5 - 10 juta & 8 \\
\hline & & Rp. $10-20$ juta & 2 \\
\hline & & $\begin{array}{l}\text { diatas Rp. } 20 \\
\text { juta }\end{array}$ & 0 \\
\hline \multirow[t]{4}{*}{6.} & \multirow{4}{*}{$\begin{array}{l}\text { TUJUAN } \\
\text { MENGIN } \\
\text { AP DI } \\
\text { HOTEL } \\
\text { PURI } \\
\text { KHATULI } \\
\text { STIWA }\end{array}$} & Berlibur & 9 \\
\hline & & Bisnis & 8 \\
\hline & & Dinas & 2 \\
\hline & & Lainnya & 1 \\
\hline \multirow[t]{5}{*}{7.} & \multirow{5}{*}{$\begin{array}{l}\text { PERTAM } \\
\text { A KALI } \\
\text { MENGEN } \\
\text { AL } \\
\text { HOTEL } \\
\text { PURI } \\
\text { KHATULI } \\
\text { STIWA }\end{array}$} & $\begin{array}{l}\text { Keluarga/saudar } \\
\text { a }\end{array}$ & 7 \\
\hline & & Relasi/teman & 6 \\
\hline & & Biro perjalanan & 3 \\
\hline & & $\begin{array}{l}\text { Iklan di media } \\
\text { massa }\end{array}$ & 2 \\
\hline & & Lainnya & 2 \\
\hline
\end{tabular}

Dari data karakteristik responden diatas, pelanggan yang sering menginap di Hotel Puri Khatuliatiwa berumur sekitar 31-40 tahun, pekerjaan 
pelanggan yang kebanyakan menginap adalah Pegawai Negeri atau Swasta. Tujuan para pelanggan Hotel Puri Khatulistiwa paling banyak adalah untuk berlibur, jumlah angka berlibur berbeda 1 angka dengan tujuan bisnis. Sebagaimana diungkapkan pada saat wawancara dengan Bapak Cahyadi selaku Manajer Sumber Daya Manusia bahwa pangsa pasar Hotel Puri Khatulistiwa adalah Government / Pemerintah. Dapat dibuktikan bahwa Hotel Puri Khatulistiwa berada di lokasi kawasan pendidikan secara tidak langsung berhubungan dengan kegiatan dinas dan juga bisnis.

Dengan memuaskan pelanggan, perusahaan dapat mempertahankan pelanggan yang telah ada dan meningkatkan jumlah pelanggan. Hal ini terjadi karena adanya promosi secara tidak langsung yang dilakukan oleh pelanggan lama kepada orang-orang disekitar mereka. Pada Tabel Karakteristik Responden, rata-rata memilih keluarga/saudara dalam mengetahui adanya Hotel Puri Khatulistiwa. Meningkatnya jumlah pelanggan ini pada akhirnya akan berpengaruh terhadap pendapatan perusahaan, sehingga kinerja keuangan perusahaan akan meningkat. Berikut disajikan dalam data lengkap yang berhubungan dengan tanggapan responden terhadap tingkat kepuasan pelanggan, yaitu :

Tabel 8. Jawaban Tingkat Kepuasan Pelanggan Terhadap Hotel Puri Khatulistiwa

\begin{tabular}{|c|c|c|c|c|c|c|}
\hline \multirow{2}{*}{$\begin{array}{l}\mathbf{N} \\
\mathbf{O}\end{array}$} & \multirow{2}{*}{$\begin{array}{l}\text { PERTA } \\
\text { NYAAN }\end{array}$} & \multicolumn{4}{|c|}{ JAWABAN } & \multirow{2}{*}{$\begin{array}{c}\text { TO } \\
\text { TA } \\
\text { L }\end{array}$} \\
\hline & & 1 & 2 & 3 & 4 & \\
\hline 1 & $\begin{array}{l}\text { Harga } \\
\text { yang } \\
\text { ditawark } \\
\text { an }\end{array}$ & $\begin{array}{c}0 \\
00 . \\
00 \\
\%\end{array}$ & $\begin{array}{c}2 \\
10 . \\
00 \\
\%\end{array}$ & $\begin{array}{l}17 \\
85 . \\
00 \\
\%\end{array}$ & $\begin{array}{c}1 \\
05 . \\
00 \\
\%\end{array}$ & $\begin{array}{c}20 \\
100 . \\
00 \%\end{array}$ \\
\hline 2 & $\begin{array}{l}\text { Pelayana } \\
\mathrm{n} \\
\text { terhadap } \\
\text { konsume } \\
\mathrm{n}\end{array}$ & $\begin{array}{c}0 \\
00 . \\
00 \\
\%\end{array}$ & $\begin{array}{c}0 \\
00 . \\
00 \\
\%\end{array}$ & $\begin{array}{c}16 \\
80 . \\
00 \\
\%\end{array}$ & $\begin{array}{c}4 \\
20 . \\
00 \\
\%\end{array}$ & $\begin{array}{c}20 \\
100 . \\
00 \%\end{array}$ \\
\hline 3 & $\begin{array}{l}\text { Kecukup } \\
\text { an } \\
\text { fasilitas }\end{array}$ & $\begin{array}{c}0 \\
00 . \\
00 \\
\%\end{array}$ & $\begin{array}{c}0 \\
00 . \\
00 \\
\%\end{array}$ & $\begin{array}{c}10 \\
50 . \\
00 \\
\%\end{array}$ & $\begin{array}{c}10 \\
50 . \\
00 \\
\%\end{array}$ & $\begin{array}{l}20+ \\
100 . \\
00 \%\end{array}$ \\
\hline 4 & $\begin{array}{l}\text { Fasilitas } \\
\text { penduku } \\
\text { ng }\end{array}$ & $\begin{array}{c}0 \\
00 . \\
00 \\
\%\end{array}$ & $\begin{array}{c}0 \\
00 . \\
00 \\
\%\end{array}$ & $\begin{array}{c}13 \\
65 . \\
00 \\
\%\end{array}$ & $\begin{array}{c}7 \\
35 . \\
00 \\
\%\end{array}$ & $\begin{array}{c}20 \\
100 . \\
00 \%\end{array}$ \\
\hline 5 & $\begin{array}{l}\text { Desain } \\
\text { interior }\end{array}$ & $\begin{array}{c}0 \\
00 . \\
00 \\
\%\end{array}$ & $\begin{array}{c}3 \\
15 . \\
00 \\
\%\end{array}$ & $\begin{array}{c}11 \\
55 . \\
00 \\
\%\end{array}$ & $\begin{array}{c}6 \\
30 . \\
00 \\
\%\end{array}$ & $\begin{array}{c}20 \\
100 . \\
00 \%\end{array}$ \\
\hline & $\begin{array}{c}\text { JUMLA } \\
\mathrm{H}\end{array}$ & $\begin{array}{c}0 \\
00 . \\
00 \\
\%\end{array}$ & $\begin{array}{c}5 \\
05 . \\
00 \\
\%\end{array}$ & $\begin{array}{c}67 \\
67 . \\
00 \\
\%\end{array}$ & $\begin{array}{l}28 \\
28 . \\
00 \\
\%\end{array}$ & $\begin{array}{l}100 \\
100 . \\
00 \%\end{array}$ \\
\hline
\end{tabular}

\section{4) Perspektif Keuangan}

Hasil wawancara dengan Bapak Cahyadi, kinerja Hotel Puri Khatulistiwa jika dilihat dari sisi keuangan berjalan dengan baik. Dilihat dari pembayaran gaji karyawan yang tidak pernah telat, sesuai dengan posisi jabatan karyawan, sesuai dengan kompetensi karyawan, menandakan keuangan Hotel Puri Khatulistiwa berjalan dengan baik. Dengan pangsa pasar Government / Pemerintah membuat Puri Hotel Khatulistiwa berani bersaing denga hotel-hotel lainnya, dengan mengedepankan fasilitas-fasilitas yang menunjang dengan kebutuhan pelanggannya.

Adanya inovasi bisnis-bisnis lainnya yang dijabarkan pada perspektif bisnis interal juga mempengaruhi pendapatan Hotel Puri Khatulistiwa. Membuka fasilitas untuk umum dapat mempromosikan Hotel Puri Khatulistiwa secara tidak langsung.

\section{KESIMPULAN}

Berdasarkan pembahasan yang telah diuraikan pada bab sebelumnya, maka dapat disimpulkan bahwa kinerja Hotel Puri Khatulistiwa ditinjau dengan menggunakan metode Balanced Scorecard pada perspektif proses bisnis internal adalah baik dengan adanya inovasi - inovasi bisnis yang dijalankan.

Kinerja Hotel Puri Khatulistiwa ditinjau dengan menggunakan metode Balanced Scorecard pada perspektif pembelajaran dan bertumbuh adalah dengan mengukur kepuasan karyawan, retensi karyawan, dan kemampuan sistem informasi. Kepuasan karyawan diperoleh 7,55\% dikategorikan baik, retensi karyawan cukup baik, dan kemampuan sistem informasi diperoleh 1,6\% dikategorikan baik.

Kinerja Hotel Puri Khatulistiwa ditinjau dengan menggunakan metode Balanced Scorecard pada perspektif pelanggan adalah dilihat dari hasil penyebaran kuesioner karakteristik responden dan kepuasan pelanggan menunjukan pelanggan puas terhadap pelayanan Hotel Puri Khatulistiwa. Kinerja Hotel Puri Khatulistiwa ditinjau dengan menggunakan metode Balanced Scorecard pada perspektif keuangan adalah baik dilihat dari beberapa aspek yang telah dijelaskan.

\section{REFERENSI}

Agung, T., Nugraha, ikhsan rizqi, Farida, I., Ameylia, R., Aprilia, U., Wiragarna, mohamad robby, \& Puspitasari, R. (2019). Strategi Peningkatan Profitabilitas Pada PT. Bank Kerta Raharja Cabang Banjaran. Jurnal Ilmiah Akuntansi Dan Keuangan, 2(1), 76-87.

Galib, M., \& Hidayat, M. (2018). Analisis Kinerja 
Perusahaan dengan Menggunakan Balanced Scorecard Pada PT. Bosowa Propoertindo. Jurnal of Akuntansi Dan Keuangan, 2(1), 92112. https://doi.org/10.22219/jrak.v5i1.4989

Gimzauskiene, E., \& Valanciene, L. (2010). Efficiency of performance measurement system: the perspective of decision making. Economics and Management.

Kaplan, R., \& Norton, D. (2016). El Cuadro de Mando Integral The Balanced Scorecard. In Gestion 2000 S.A,Ediciones.

Kaplan, R. S., \& Norton, D. P. (1996). strategic learning \& the balanced scorecard. In Strategy \& Leadership. https://doi.org/10.1108/eb054566

Kurniasari, V., \& Memarista, G. (2017). Analisis Kinerja Perusahaan Menggunakan Metode Balanced Scorecard ( Studi Kasus Pada PT . Aditya Sentana Agro ). Jurnal AGORA, 5(1), 7.

Mahmudah. (2015). Analisis Pengukuran Kinerja Perhotelan dengan Pendekatan Balanced Scorecard (BSC). Jurnal Pendidikan, Komunikasi, Dan Pemikiran Hukum Islam, 7(1), 154-168.

Mulyadi. (2001). edisi 3. Akuntansi manajemen, Konsep, Manfaat, dan Rekayasa. In Universitas Gadjah Mada.

Nugrahini, I. ayu putu, Ratnadi, ni made dwi, \& Putri, I. G. A. M. asri dwija. (2016). Penilaian Kinerja Berdasarkan Balanced Scorecard Pada Badan Penanaman Modal dan Perijinan
Daerah Kabupaten Tabanan. E-Jurnal Ekonomi Dan Bisnis Universitas Udayana, 5(4), 829-856.

Putra, R. E. (2014). Analisis Kinerja Perusahaan dengan Metode Balanced Scorecard (Studi Kasus pada PT.Putra Tidar Perkasa). Jurnal Measurement, 8(1), 37-50. https://doi.org/10.1515/pubhef-2004-2105

Simarmata, H. M. P., Saragih, D. Y., \& Panjaitan, N. J. (2017). Peningkatan Kualitas Layanan Kepuasan Pelanggan Hotel. Jurnal EK \& BI, 43-51.

Styaningrum, F. (2015). Perumusan Strategi Perusahaan Berbasis Balanced Scorecard Pada Kusuma Sahid Prince Hotel Surakarta. Jurnal Akuntansi Dan Pendidikan, 4(1), 59-67.

Styaningrum, F., Sulistyadi, K., \& Riani, asri laksmi. (2014). Analisis Kinerja Perusahaan Dengan Metode Balanced Scorecard Pada Kusuma Sahid Prince Hotel Surakarta. Jurnal Pendidikan Insan Mandiri, 3(1), 55.

sugiono. (2011). metode penelitian pendidikan (pendekatan kuwantitatif,kuwalitatif,R\&D). In Alfabbeta Pres.

Sumani. (2016). Pengukuran Kinerja Bisnis Melalui Pendekatan Balanced Scorecard Dan Analytical Hierarchy Process (Ahp). Ekuitas (Jurnal Ekonomi Dan Keuangan), 20(4), 455472.

https://doi.org/10.24034/j25485024.y2016.v20 i4.1842 